\title{
Strategic Risk Management among Small Enterprises in the Construction Industry
}

\author{
Tlangelani Baloyi ${ }^{1^{*}}$ and Aghaegbuna Ozumba ${ }^{1}$ \\ ${ }^{1}$ U niversity of the W itwatersrand, 1 J an Smuts A ve, J ohannesburg 2000, South A frica
}

\begin{abstract}
The purpose of this study is to develop knowledge around the practice of risk-management by small enterprises in the construction sector. The study will discuss the shortfalls in practice, and possible riskmanagement strategies suggested. This research is a literature review based study. An integrative review of a purposive sample of literature was used to generate articles discussing SMMEs and their business challenges. The search narrowed down to risk management articles with a specific focus on strategic risk management. The significant limitation to the study is the theoretical nature at this stage. Findings, however, suggest that nonsystematic risk management in business operations by small enterprises and lack of innovative strategies that accommodate for market competition, hinder their transition to medium enterprises. However, small enterprises that practice strategic risk management stand a better chance of transitioning into medium enterprises because of their better understanding of risks and resource organization.
\end{abstract}

Keywords: business, enterprise, risk, SM M E, strategic risk management.

\section{Introduction}

Small, Medium and Microenterprises (SMMEs), are important in the economic progression of countries through job creation, and entrepreneurial innovation [1]. Such entities have an employment level of fewer than 250 employees. Small enterprises, in particular, have employees ranging from 5-100 depending on their country and industry. Any enterprise's development greatly relies on its ability to efficiently manage its risks [2]. Risks will punitively affect an enterprise if adequate mitigation measures are not effectively structured [3]. A common method of managing an enterprise's threats is their risk management plan. Risk management is identified as an essential element in the running of businesses as it helps to yield the highest returns for an enterprise by minimizing unforeseen costs accruable from risks [4]. Strategic risk management, in particular, allows an enterprise to align its management practices to its long-term planning based on its organizational goals and objectives [5]. Risk management is therefore broad and interpreted differently according to the individual knowledge backgrounds. Nevertheless, the strategy chosen to deal with risks

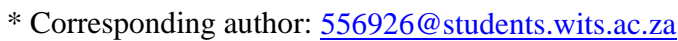


should fulfil the generic aim of risk management [6]. However, Venturini and Verbano [7] assert that risk management strategies practised by small enterprises are likely to be less effective due to their reduced risk management abilities.

The business for small enterprises in construction occurs in the form of projects secured through bidding processes. The enterprise will bid as a contractor, subcontractor, consultant or special skills experts. The stated nature of business occasions occurs with varying risks [8]. The enterprise needs to develop strategies that enable it to best factor for such risks [9]. However, a manager, owner, or employee will recognize risks according to their cognition of threats [1]. The training and knowledge a manager has about risks, inform their risk management decisions [2]. Unfortunately, for most small enterprises, there is evidence of deficiency in strategic risk management, resulting in slow business development and transition to medium scale enterprises [9]. Consequently, the pertinent research question is: What hinders small enterprises in construction from the effective practice of strategic risk management in their business planning and operations?

Ekwere [4], states that small enterprises have more challenges in practising conventional risk management when compared to medium and large enterprises. They tend to emulate large enterprise practices instead of developing approaches that will match their risk appetite and risk handling capabilities. Thus only a few enterprises practice strategic risk management with proof that it develops the business of small enterprises [6]. Nevertheless, there is a scarcity of information about the general inadequacy of strategic risk management practice by small enterprises. In an emerging economy context such as South Africa, small enterprises are vulnerable to internal structural problems when compared to their counterparts in other developing countries [10]. They lack specialized services and products that they can introduce in the market, and as a result, have to compete with large enterprises to offer the same products and services [11]. The critical emphasis on small business survival and transition in South Africa is highlighted in the relevant literature such as [12] who assert that due to the $26.7 \%$ unemployment rate in the country, SMMEs need to create the majority of the needed jobs. This makes small-enterprise development highly critical in such contexts. In the absence of adequate information, there is a need to identify risk management practices gaps by small enterprises in the construction industry. There is also a need to articulate such findings towards suggesting feasible solutions that will assist in developing well adapted long-term strategies to mitigate their business risks. The current study aims to investigate existing risk management practices within the construction industry and assess the barriers hindering small enterprises from the conventional practice, with particular reference to the South African context as a possible setting for empirical data in subsequent stages. The methodology presented hereunder was used in an attempt to achieve the study aim.

\section{Methodology}

The study is at the preliminary stage of a broader research project. An integrative literature review approach of purposively sampled literature on SMMEs and their business challenges was used. The purposive sampling strategy was used to find articles discussing small enterprises and their development limitations. Articles and papers for the literature review were retrieved from the following databases: Emerald, Google Scholar, Science Direct, and Taylor \& Francis. The following keywords were used for searching through databases: Challenges affecting SMMEs, business enterprise, business strategy, risks, risk management, risk management adoption, risk management in SMMEs, risk management in construction, strategic risk management, strategic risk management in small enterprises in construction, market niche, and market niches in construction. 
The staged approach to the integrative literature review is as follows:

- A quick perusal of abstracts was conducted to assess the relevance and currency of the papers. The findings in the studied articles demonstrated poor risk management as a barrier to business development and effective running of small enterprises.

- Following the first step, a search for articles discussing how enterprises can effectively practice risk management was conducted.

- In order to relate findings to the construction industry, the literature on strategic risk management in construction was also reviewed.

The stated approach assured alignment to the broader focus of risk management and strategy. The two main knowledge areas were combined to get a more unobstructed view of the challenges around strategic risk management implementation in construction. An annotated literature review table with the following headings was used to summarize essential information from the reviewed papers: Full reference, research problem, consequences of the problem, methods, findings, theory, and relevance of the study. Following an analysis of the information extracted from the review template, available information was grouped under the given headings and resulting sub-headings. Results are presented hereunder.

\section{Knowledge from Previous Studies}

\subsection{Risk}

As much as there are various definitions of risk, the common defining attributes are uncertainty and the consequences the risk brings, either positive or negative, to any organizations' objectives [13]. Risk and uncertainty are often used interchangeably. However, they differ on the basis that an enterprise knows risk because its probability can be calculated; whereas, uncertainties cannot be predicted [14]. Risk classification is greatly affected by one's knowledge about risks. Essentially the concept of risk lies in a person's knowledge and valuation of risks, thereby making risk perception a strong factor for risk behaviour [15]. Common types of risk include credit risk, market risk, project risk, business risk, strategic risks, operational risks, reputational risks, liquidity risks, political risk, employee risk, enterprise risk and financial risk [16]. The current study focuses on business risks.

Business risk entails internal and external events of which their uncertainties need to be understood by an enterprise to effectively implement strategies that direct the business to achieve its goals and objectives while maximizing the value for shareholders [11]. Types of business risks include: strategic risk, reputational risk, compliance risk, reputational risk, financial risk and others [15]. Arguably with business risks comes the need for risk management.

\subsection{Risk Management}

According to Verbano and Venturini [7], risk management (RM) assists enterprises with reducing uncertainty and ensuring continuity in production and market trading whilst maximizing profits through costs reduction. There are various definitions of risk management, for which definitions, the authors have articulated the following origins:

- Risk management involves measuring risks through the use of a geometric mean and distributing it across a set of events that are dependent, to minimize it. 
- Economic, monetary losses, damage to property, as a resulting from an inherent uncertainty related to the action taken.

- Regressive and unfavourable outcomes of an incident, which might hinder the success of operating, strategic and monetary goals of an enterprise.

Venturini and Verbano [7] also assert that RM should create value, consist of strategic planning, be systemic and structured, be transparent and inclusive, and be responsive to change, and account for human factors.

Conventional RM procedure explains that all risks need to be identified and known to determine their severity and management style [17]. The risks will then be analyzed and prioritized, to plan for mitigation strategies. An RM professional will need to monitor and evaluate the usefulness of the selected management strategies [18]. The RM process arguably needs to be systematic for efficiency. Mills [19] explains that the greater advantages of a systematic risk management approach include the ability to rank risks, identifying opportunities to improve project performance, and making informed decisions on mitigation plans. It also includes defining the roles of the enterprise and other stakeholders in risksharing and transfer. Types of risk management include: Enterprise RM, Operational RM, Currency RM, Financial RM, Market RM, Software RM, RM, Quantitative RM, Commodity RM, Bank RM, Project RM, Integrated RM, Technology RM, IT RM and Strategic RM [11]. The current study is focused on strategic risk management.

Enterprises need adequate RM principles to survive. The requirement can be achieved through long-term planning and strategic thinking [20]. An enterprise needs to identify its risk appetite to develop a hierarchy of strategies [21]. Mainardes et al. [6] highlight that the notion of strategy has been extensively used in the management field and describes anything formulated in a particular environment, to be the course of action in improving a specific aspect of a company based on its goals and objectives. Lechner and Gudmundsson [5] discovered that an enterprise's advancement depends on its entrepreneurial behaviour and the application of competitive strategies in its business planning. Mainardes et al. [6] emphasize however that it is futile to have strategies that will not work for the enterprise, thus it is crucial for new/young enterprises owners to have the capacity to develop and manage strategies that will enable the enterprise to factor out market challenges, reaching their objectives in the short, medium and long terms. The greater advantage brought by strategic risk management to an enterprise is its ability to increase the enterprise's value, especially for enterprises sensitive to market fluctuations [22].

\subsection{Risk Management in Construction}

Construction businesses face many risks due to in-built uncertainties related to construction projects [20]. Risk management is, therefore, an essential aspect of decision-making processes in construction enterprises [19]. As mostly observed in the industry, the risk is likely to be shifted to small contractors. Their poor long-term planning leaves them financially stranded in such cases [23]. Risk identification is a crucial step in decision making when an enterprise is uncertain about the probability of unforeseen risks [24]. Small contractors will thus need a reliable tool that measures the extent of the potential risk because a precise estimate of risk can be time-consuming [25]. Ranking of the importance of risks differs among developed and developing countries. For example, UK construction enterprises prioritize changes in the initial design, while their counterparts in Ghana prioritize delay in payment from the client [26]. The list of risks in construction includes: natural disasters, subcontractor and supplier issues, equipment damage and theft of tools, building material availability, poorly administered contracts, undefined scopes, drawings that are not complete, management of changes in orders, and poor risk management [27]. The different lines of business for contractors and consultants in construction dictate the prioritization 
of risks. Contractors will factor in weather, groundworks, contaminants, and construction methods. The hierarchy will differ for consultants. They consider poor communication among team members in a project and inflation when treating their risks [26].

Chileshe and Kikwasi [26] regarding the adaptation of risk assessment and management by SMMEs in Tanzania, present a discussion of the challenges to risk management as identified by other researchers around the globe. Interestingly, developed countries are not exempt from the barriers to the systematic practice of risk management. The table below depicts the findings:

Table 1. Risk Management Adoption for Construction Enterprises around the Globe

\begin{tabular}{|c|c|}
\hline Country & Barriers \\
\hline $\begin{array}{l}\text { Hong } \\
\text { Kong }\end{array}$ & $\begin{array}{l}\text { Challenges in getting input estimates and their probability assessment; Time } \\
\text { constraints; challenges in understanding risk management techniques; IT resources and } \\
\text { managerial support. }\end{array}$ \\
\hline K orea & $\begin{array}{l}\text { The absence of awareness and expertise in risk management practices; Tangible risk- } \\
\text { probability calculations. }\end{array}$ \\
\hline US & Personal prejudices; traditional norms. \\
\hline Ghana & $\begin{array}{l}\text { Lack of experience; lack of facts and figures, coordination among stakeholders; } \\
\text { accessibility of risk-management specialists; time limitations; lack of knowledge and } \\
\text { expertise. }\end{array}$ \\
\hline UK & $\begin{array}{l}\text { Late start to projects; inexperienced employees; attitude towards risk; not robust } \\
\text { enough and risk identification incompetency. }\end{array}$ \\
\hline Singapore & $\begin{array}{l}\text { Competition among SM ME contractors; the complexity of analytical tools; lack of } \\
\text { prospective benefits; budget deficiency; lack of government legislation; lack of } \\
\text { knowledge; lack of trained professionals; lack of time; low-profit margin; and not } \\
\text { economical. }\end{array}$ \\
\hline Tanzania & $\begin{array}{l}\text { Risk management awareness; coordination among project team members; risk } \\
\text { management styles; effective use of tools and methods; enterprise strategic objectives; } \\
\text { internal and external environment; less qualified risk professionals; client requirements } \\
\text { and cooperative culture. }\end{array}$ \\
\hline
\end{tabular}

Source: Chileshe and K ikwasi [23]

As seen in the table, the critical challenges to adopting a conventional risk management approach are affected by the poor awareness of risk handling techniques, enterprise managers' lack of risk management, time constraints, inadequately trained risk personnel, and poor budget allocation for risk training and practice. If an enterprise fails to practice conventional risk management, there is little chance of integrating other risk management techniques. In summary, poor adoption RM still poses a great threat to the development of small enterprises.

\section{Additional Findings in Literature}

- Small and medium enterprises have challenges embracing risk analysis strategies that are qualitative-based due to their reduced knowledge and practice of risk management and lack of trained specialists to perform risk identification [20].

- Construction small enterprises fail to practice systematic risk management because of limited qualitative and quantitative data from previous projects that could enable them to establish a proper risk response strategy for their enterprise [17]. 
- Identified the top three critical success factors for company success by Turkish construction company managers/owners include: business management, financial conditions, and owner-manager characteristics [28].

- Developing an effective business strategy is critical for business stability when an enterprise is small and undeveloped [5].

- Small enterprises practising strategic risk management stand a better chance at survival if the principles are applied at an organizational level [21].

According to [29] there are options available to construction enterprises to the best factor for risks while maximizing profits and business growth. The following suggestions were made for contractors when designing their risk handling methods:

Table 2. Risk Mitigation Strategies for Construction Enterprises

\begin{tabular}{|c|c|}
\hline Risk Response Strategy & Risk Handling Method \\
\hline Risk avoidance & $\begin{array}{ll} & \text { Increase unit cost or overhead } \\
- & \text { D evelop substitutes for risk events } \\
\text { - } & \text { Remove risk events by avoiding them }\end{array}$ \\
\hline Risk transfer & $\begin{array}{l}\text { - } \quad \text { Use insurance } \\
\text { - } \quad \text { Subcontract work } \\
\text { - } \quad \text { Train and educate staff }\end{array}$ \\
\hline Risk mitigation & $\begin{array}{l}\text { - } \quad \text { Develop a strategic staffing plan } \\
\text { - } \quad \text { U se proven construction materials and methods } \\
\text { - } \quad \text { Safeguard both workers and property } \\
\text { - } \quad \text { Provide best supplies (e.g., computers, equipment, etc.) }\end{array}$ \\
\hline Risk-retention & $\begin{array}{l}\text { - } \quad \text { Prepare contingency planning } \\
\text { - Accept profit losses }\end{array}$ \\
\hline
\end{tabular}

Source: [29]

\section{Discussion}

The success of enterprises relies essentially on the implementation of effective risk management. This assertion holds for small enterprises also. However, risk management practices by small enterprises do not seem to be in line with known/conventional approaches, despite given benefits. Essentially there is the case of non-systematic risk management in business operations by small enterprises. They also seem to lack innovative strategies and adequate sensitivity to market competition. Evidence from the literature suggests that small enterprises are currently in need of a holistic risk management approach. A possible solution for their competitiveness and growth is strategic risk management. Enterprises need to develop their risk integrity, and an efficient RM, to maximize organizational goals. In Falkner and Hiebl [2]'s study, a holistic risk management approach is suggested for small enterprises as a measure to bridge the gap between theoretical and practical risk management competencies. In an earlier study, owners and managers of small enterprises, are advised to be sensitive to business and managerial risks when planning and executing business strategies as part of RM [29]. However, there is currently limited research on how small construction enterprises practice risk management in their daily business activities and how this informs decision-making [3]. A notable recommendation to small enterprises as highlighted by Tshikhudo et al. [10] is the need to invest in risk management training 
programs. Mainardes et al. [6] support this recommendation and state that small enterprises receiving risk management education and training, better inform their business objectives and competitive strategies. It is also advised that small enterprises engage in business collaborations and ventures to maximize their performance, particularly in countries with unstable economies [30].

\section{Conclusions}

The purpose of this study was to understand risk-management practices by small businesses within the construction sector and the implications. This stage of the study is a literature review. There is, therefore, an opportunity to explore other relevant theories and bodies of knowledge, beyond the current study. Findings from this stage of the research can be summarized thus: Small enterprises that have adopted strategic risk management stand a better chance of survival due to their improved capacity for managing business risks. Furthermore, the emerging relationships of concepts explored in the study also highlight the need for emphasis on niche and aligned business risk strategies, as presented in Figure 1.

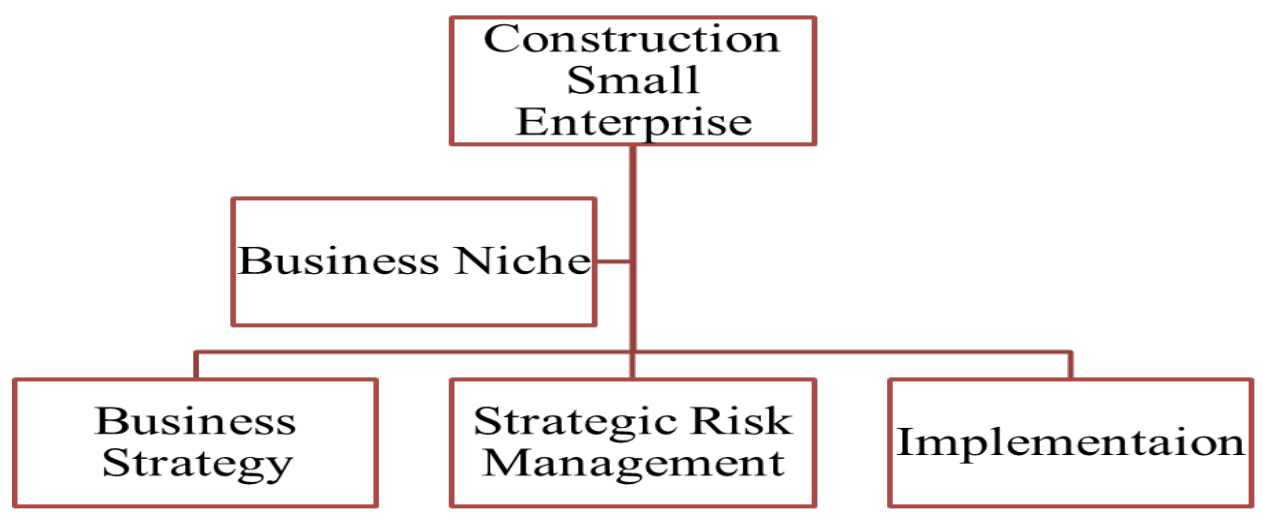

Fig. 1. The proposed relationship of concepts identified in the literature.

Figure 1 shows the emerging relationship of concepts explored in the current study. From Figure 1, small construction enterprises need to develop a specific market product to specialize in. They also need to establish business strategies that will optimize their profits. Since the construction industry is very competitive, it is important for the strategy developed to align with the principles of strategic risk management for an effective business transition.

The stated summation at this stage remains to be given specific cause and effect description. It is necessary to understand how business failure/non-transition to higher levels for small businesses, is inferred by the identified gaps. It is essential to provide the empirical basis for the identified gap and the nature of the impact, for further discussion. The dearth of relevant information in this regard is supported by [31] and [32], and the various suggestions by authors such as Tshikhudo et al. [10] and Kossyva et al. [30]. Future research should focus on empirical studies of challenges to the effective practice of risk management for small enterprises in construction. Such studies should emphasize strategic risk management.

Furthermore, the possible link between business synergies and improvement of strategic risk management practice among small enterprises should be explored. Figure 1 is proposed as the basis for developing a conceptual framework, in the next stages of this research. Regardless of the theoretical nature of the current study, it is very relevant to construction industry development because risk management is a major factor in business growth and 
competence. The current study has attempted to articulate knowledge on the practice of strategic risk management by small enterprises in construction, which constitutes a knowledge gap area. The current study has also proposed a conceptual relationship which can be utilized as a basis for developing a conceptual framework for empirical studies in the identified knowledge gap.

\section{References}

1. T. Mazzarol, D.N. Clark, S. Reboud, Strategy in action: Case studies of strategy, planning and innovation in A ustralian SMEs, Small Enterprise Research 21(1):54-71 (2014)

2. E.M. Falkner, M.R.W. Hiebl, Risk management in SMEs: a systematic review of available evidence, The Journal of Risk Finance 16(2):122-144 (2015)

3. S. Laryea, W. Hughes, Risk and Price in the Bidding Process of Contractors. J ournal of Construction Engineering and $M$ anagement 137(4): 248-258 (2011)

4. N. Ekwere, Framework of effective risk management in small and medium enterprises (SMES): A literature review 23-28 (2016)

5. C. Lechner, S.V. Gudmundsson, Entrepreneurial orientation, firm strategy and small firm performance. International Small Business Journal 32(1):36-60 (2014)

6. E.W. Mainardes, J. Ferreira, M.L. Raposo, Strategy and Strategic Management Concepts: A re They Recognised by Management Students? E+M Ekonomie a Management 17(1):43-61 (2014)

7. C. V erbano, K. V enturini, M anaging Risks in SM Es: A Literature Review and Research A genda, Journal of technology management \& innovation 8(3):33-34 (2013)

8. Taroun, Towards a better modelling and assessment of construction risk: Insights from a literature review, International Journal of Project Management 32(1):101-115 (2014)

9. M.P. Johnson, Sustainability M anagement and Small and M edium-Sized Enterprises: Managers' Awareness and Implementation of Innovative Tools: Sustainability Management Tools and SMEs, Corporate Social Responsibility and Environmental Management 22(5):271-285 (2015)

10. L. Tshikhudo, C. Aigbavboa, W. Thwala, Critical Success Factors for the survival of small, medium and micro enterprise construction companies in the South A frica construction industry 5 (2015)

11. Y. Smit, A literature review of small and medium enterprises (SM E) risk management practices in South A frica, African Journal of Business Management 6(21) (2012)

12. J. Nonyana, P. Njuho, Modelling the length of time spent in an unemployment in an unemployment state in South A frica, South A frican Journal of Science 114(11/12):1-7 (2018)

13. I.J. Dabari, S.Z. Saidin, A Theoretical Framework on the Level of Risk Management Implementation in the Nigerian Banking Sector: The Moderating Effect of Top M anagement Support, Procedia - Social and Behavioral Sciences 164:627-634 (2014)

14. J.G. V argas-Hernández, Modeling risk and innovation management, 14 (2011)

15. F. van W insen, Y. de M ey, L. Lauwers, S. V an Passel, M. Vancauteren, E. Wauters, Determinants of risk behaviour: effects of perceived risks and risk attitude on farmer's adoption of risk management strategies, Journal of Risk Research 19(1):56-78 2016

16. D. Griffin, Types of Business Risk (2018), Smallbusiness.chron.com. A vailable from: https://small business.chron.com/types-business-risk-99.html [A ccessed 29 J un. 2018].

17. A.F. Serpella, X. Ferrada, R. Howard, L. Rubio, Risk Management in Construction Projects: A Knowledge-based Approach, Procedia - Social and Behavioral Sciences 119:653-662 (2014)

18. L. W illiams, Risk Management 1-3 (2004) 
19. Mills, A systematic approach to risk management for construction, Structural Survey 19(5):245-252 (2001)

20. Y. Y oon, Z. Tamer, M. Hastak, Protocol to Enhance Profitability by M anaging Risks in Construction Projects, Journal of Management in Engineering 31(5):04014090 (2015)

21. C. Adendorff, G. Appels, B. Botha, Strategic management: An Eastern Cape construction SME case study, Strategic management 24 (2011)

22. S.W. Rawls, C.W. Smithson, Strategic risk management, Journal of Applied Corporate Finance 2(4):6-18 (1990)

23. M. Hardie, Influences on innovation in small Australian construction businesses, Journal of Small Business and Enterprise Development 17(3):387-402 (2010)

24. A.A.G. Hassanein, H.M.F. Affify, Risk management for contractors: a case study of power station projects in Egypt 12(3): 165-179 (2007)

25. Jannadi, S. Almishari, Risk A ssessment in Construction, Journal of Construction Engineering and Management 129(5):492-495 (2003)

26. N. Chileshe, G.J. Kikwasi, Risk assessment and management practices (RA M P) within F. Racher, Over Promising, Under Delivery, Why Y our A pproach to Bidding Could Be Killing Your Business (2015) [Online] Available from: http://www.riskdecisions.com/risk-analysis-for-winning-bids/ [Accessed 16 October 2017].

27. the Tanzania construction industry: Implementation barriers and advocated solutions, International Journal of Construction Management 14(4):239-254 (2014)

28. K. Jones, 4 Common Risk Factors on Construction Projects, ConstructConnect.com. [online] ConstructConnect.com. A vailable from: https://www.constructconnect.com/blog/operating-insights/4-common-risk-factors-onconstruction-projects/ [A ccessed 31 Jul. 2018]

29. G. A rslan, S. Kivrak, Critical Factors to Company Success in the Construction Industry 2(9):4 (2008)

30. D. Berkeley, P.C. Humphreys, R.D. Thomas, Project risk action management, Construction Management and Economics 9(1):3-17 (1991)

31. D. K ossyva, K. Sarri, N. G eorgopoulos, Co-opetition: A business strategy for SM ES in times of economic crisis 18 (2014)

32. N. Georgopoulos, D. Kossyva, K. Sarri, Co-epitition: A Business Strategy for SM Es in times of crisis, South-Eastern Europe J ournal of Economics 1: 89-90 (2014) 